\title{
Non-urgent care in the hospital medical emergency department in France: how much and which health needs does it reflect?
}

\author{
Thierry Lang, Alain Davido, Bakary Diakité, Emmanuelle Agay, Jean François Viel, \\ Bernard Flicoteaux
}

\section{Service de \\ Biostatistique et \\ Informatique \\ Médicale, Groupe \\ Hospitalier \\ Pitié-Salpétrière, \\ Assistance-Publique \\ Hôpitaux de Paris, 91 \\ Bd de l'Hôpital, 75013 \\ Paris, France \\ T Lang \\ B Diakité}

Département des Urgences Médicales, Groupe Hospitalier Pitié-Salpétrière, Assistance- Publique Hôpitaux de Paris, Paris, France

A Davido

Département de Biostatistique et Informatique

Médicale, Centre

Hospitalier

Universitaire de

Besançon, France

E Agay

J F Viel

Département des

Urgences Médicales,

Centre Hospitalier

Universitaire de

Besançon, France

B Flicoteaux

Correspondence to:

Dr T Lang.

Accepted for publication April 1996

\begin{abstract}
Objectives - The goal was to describe the use of the medical emergency department as a source of non-urgent medical care in order to assess unmet health care needs among its users. The specific objectives were thus to assess the proportion of emergency department visits for nonurgent medical care and to describe those who used the department for this reason.

Design - A cross sectional study was performed at the emergency department in two hospitals (around 12000 visits per year each). Subjects were interviewed before and after the visit using a standardised questionnaire.

Setting - The medical emergency department of two university hospitals, one in Paris and one in Besançon (France).

Subjects - Each patient aged 15 and more attending the emergency department for a visit during 40 randomly selected periods of 12 hours was included.
\end{abstract}

Main outcome measures - A definition of urgent care was adopted before the beginning of the study. Four expert judgments were then used for each case to determine whether the reason for the visit was urgent or not.

Results - Altogether 594 patients in the Paris emergency department and 614 in the Besançon one were included. In Besançon, the patients were older, a general practitioner was more often cited as the regular source of care, and the percentage of subsequent hospital admission was higher than in Paris (71\% versus 34\%). The non-urgent visits were estimated to account for $35 \%$ and $29 \%$ of the visits in Paris and Besançon respectively. Patients using the emergency department for a non-urgent visit were younger than other patients. More of them were unemployed, homeless, born outside of France, and without health insurance.

Conclusions - Non-urgent use of the emergency department was observed in about one third of the visits. Groups using the department for primary care and/or non-urgent care were mostly young and socially fragile, with no regular source of health care. Their poor health condition suggests that there is a need for a structure providing primary care both inside and outside 'normal' working hours.

(F Epidemiol Community Health 1996;50:456-462)

Although an increasing number of visits to hospital emergency departments has been described in France, ${ }^{12}$ a decreasing proportion of these visits results in a hospital admission. The use of the emergency department as a source of primary care for many patients has been suspected as a cause of this finding. ${ }^{2}$ In France, the proportion of non-urgent visits has been estimated to be between 28 and $76 \%$ in a paediatric emergency department, ${ }^{34}$ but we have no data available for adults. In Europe, values around $40 \%$ have been reported. ${ }^{56}$ In the USA, this proportion was found to be variable, some values were, however, very high, ranging from 5 to $82 \% .^{7}$ Although this phenomenon has been suggested in France, it has not been quantified, ${ }^{2}$ and the characteristics of the population who use the emergency department for non-urgent care have not been described.

In the context of increasing social difficulties and health inequalities in France, ${ }^{8}$ we believed that the emergency department might be used for primary health care by some groups of the population characterised by poor social status as well as poor health status. If this were true, these health needs would need to be taken into account, since given the organisation, the training of the staff, and the usual overcrowding of the emergency department in a French hospital, quality care could not be delivered to these particular patients. In fact, the emergency department is currently organised as an acute care delivery structure. If we regard 'continuity' as, 'the extent to which medical care services are received as a coordinated and uninterrupted succession of events consistent with the medical care needs of patients, ${ }^{9}$ it is evident that organising continuity of care has not been included in the objectives of the emergency department. Those groups who use the emergency department as a souce of primary care, therefore, may not receive good quality care in the long term.

The specific goal of the study was thus to assess the percentage of non-urgent visits to the emergency department and the characteristics of those attending for non-urgent reasons. Since the Paris area is unique with regard to the social and economic background of the 
population, as well as the health structures and health care utilisation, it was decided to study the situation in both Paris and in one of the French regional university hospitals, Besançon.

\section{Methods}

\section{GENERAL DESIGN}

A cross sectional study was performed in the emergency department of two university hospitals, the Pitié-Salpétrière Hospital, Paris and the Jean Minjoz Hospital, Besançon. The Pitié-Salpétrière Hospital is a university hospital, in the centre of Paris. With more than 2000 beds, it is the biggest in the Paris hospitals organisation (Assistance Publique-Hôpitaux de Paris). More than 18000 visits per year to the emergency department have been recorded since 1992. The Jean Minjoz Hospital is located in Besançon, in the Franche-Comté region. The number of beds is around 1300 and 12000 visits to the emergency department were registered in 1992 .

Each person aged 15 years and more was eligible for the study. The patients were interviewed prospectively before the examination by the doctor. The standardised questionnaires used in Paris and Besançon were basically the same. Minor differences were due to the local environment and habits. When the patients could not be interviewed because of their health status, the relatives were asked to provide information. It was decided to exclude, if necessary, patients whose situation was difficult, for instance, after an attempted suicide. The data were collected by a medical or paramedical interviewer who was not involved in care.

In Paris, the study was performed over two periods - from March to June 1993 and January to February 1994. In Besançon, the study period was September to December 1993. In each hospital, 40 periods of 12 hours were randomly selected. As a result, day and night shifts, weekdays, and weekends were included. Given the mean number of visits, a minimum of 400 patients per centre was expected. The consent of the subjects was obtained and information on confidentiality was given, as requested by the Commission Nationale Informatique et Liberté (CNIL), which was informed of the study.

Information on social and demographic characteristics, health status, and preventive care was obtained from the patient. Housing conditions were classified as stable; precarious; those living in the homes of friends or relatives, a hotel, or an ambulatory home and; those who were homeless or living in shelters; and those resident in institutions for elderly.

Profession and social category were recorded and coded according to the classification from the Institut National de la Statistique et des Etudes Economiques (INSEE). ${ }^{10}$ The reason for the visit as stated by the patient and the medical diagnosis recorded by the doctor on duty were coded according to the French version of the International Classification of Primary Health Care (CISP). ${ }^{11}$ These two codes were applied by the principal investiga- tor at each centre. Agreement with coding was assessed on a random sample of 200 records in each centre. These records were coded in Paris and in Besançon independently. The concordance between these two investigators was found to be fair (Kappa coefficient $=0.84$, 0.86 , and 0.88 respectively for professional and social category, reason for the visit, and medical diagnosis).

DEFINITION OF NON-URGENT CARE

The following definition of urgent care was adopted before the beginning of the study. A visit was considered as urgent if one of the following conditions was present: immediate care was necessary within four hours in order to avoid severe consequences for the patient (extreme emergency); his (her) health condition required care within 24 hours or the technical equipment of the hospital had to be used for diagnosis or therapeutic purposes (emergency); although the vital or functional prognosis was not threatened within 24 hours, the patient was worried by the appearance or the recent worsening of symptoms (subjective emergency).

Conversely, a visit was considered as nonurgent if the symptoms were not recent, or recent and minor, without any feeling of emergency on the part of the patient. The experts agreed on being more specific than sensitive to the non-urgent cases. It was thus decided that when investigations occurred during the visits, ambiguous cases would be considered as urgent.

Each case was coded independently by four observers, the doctor and the nurse on duty as well as by two seniors specialists in emergency medicine, using the information from the patient's record.

In the absence of a clear cut definition of a non-urgent case and in order to obtain the best estimate from the four experts, we used a method proposed by Hui and Walter. ${ }^{14}$ This method allows the estimation of the prevalence of a dichotomic problem and the sensitivity and specificity of several observers where no gold standard can be used. This method does not preclude hypothesis on parameters. The estimation of the parameters is based on the maximisation of the likelihood. Where the prevalence of the phenomenon is high, which it was in our case, the method has been shown to be valid. ${ }^{15}$ In our study, the following parameters were to be estimated: the prevalence of non-urgent cases, the sensitivity and specificity of the two senior experts, and the sensitivity and specifity of the doctor and the nurse on duty. The stability of the results was estimated through a procedure using all combinations of three out of four observers and comparing the estimations obtained.

\section{STATISTICAL METHODS}

Qualitative variables were compared using the $\chi 2$ test and quantitative variables using the Student's $t$ test. The logistic regression analysis was performed with the $S A S$ statistical package. ${ }^{13}$ The criteria for inclusion of variables in the multivariate analysis were a $\mathrm{p}$ value $<0.25$ 
Table 1 Characteristics of the patients who visited the two emergency departments (ED)

\begin{tabular}{|c|c|c|c|}
\hline Variables & $\begin{array}{l}\text { Paris } \\
(n=594) \\
\%\end{array}$ & $\begin{array}{l}\text { Besançon } \\
(n=614) \\
\%\end{array}$ & $p$ \\
\hline Sex (male) & 59.9 & 53.4 & 0.02 \\
\hline \multicolumn{4}{|l|}{ Age (y): } \\
\hline$<30$ & 26.1 & 23.3 & \\
\hline $30-64$ & 56.7 & 42.7 & \\
\hline$>=65$ & 17.2 & 34.0 & $<0.00001$ \\
\hline \multicolumn{4}{|l|}{ Birthplace: } \\
\hline France & 73.3 & 85.2 & $<0.00001$ \\
\hline \multicolumn{4}{|l|}{ Reference to the ED: } \\
\hline Self referral & 38.3 & 12.4 & \\
\hline General practitioner & 4.0 & 49.1 & \\
\hline $\begin{array}{l}\text { Others (referrals, emergency care, } \\
\text { ambulance, police) }\end{array}$ & 57.7 & 38.5 & $<0.00001$ \\
\hline \multicolumn{4}{|l|}{ Result of the visit to the ED: } \\
\hline Hospital admission & 34.5 & 70.5 & $<0.00001$ \\
\hline Stated usual source of health care: & & & \\
\hline General practitioner & 67.0 & 89.5 & $<0.00001$ \\
\hline
\end{tabular}

in the univariate analysis. Age and sex were systematically introduced into the model.

\section{Results}

CHARACTERISTICS OF THE POPULATION AS A WHOLE

Five hundred and ninety four patients were included in Paris and 614 in Besançon. The response rate was over $92.9 \%$ in Paris and $96.3 \%$ in Besançon. In Paris, non responders did not differ from responders with regard to age or sex. In Besançon, patients who refused the questionnaire were younger and those who could not answer were older.

The patients in the Besançon emergency department were older than those in Paris (table 1). As a result, the percentage of retired persons was higher in Besançon than Paris (36.3 versus $15.1 \%$ ). In Paris compared with Besançon, a higher percentage of subjects was homeless (9.2\% in Paris, $1.8 \%$ in Besançon), had no stable housing $(9.2 \%$ versus 18.8 respectively), lacked health insurance $(12.3 \%$ versus $8.1 \%$ respectively), and one subject out of two stated that they lived alone $(51.5 \%$ versus $48.1 \%$ respectively). The proportions of single, widowed, and persons living in couples did not differ between the two cities.

More patients in Besançon than in Paris stated that they had a GP (table 1). In Paris, $14 \%$ of the patients stated that the emergency department was their usual source of care. Similarly, a higher percentage of patients was

Table 2 Estimations of the sensitivity, specificity, and prevalence of non-urgent visits to the emergency department

\begin{tabular}{|c|c|c|c|c|}
\hline \multirow[t]{2}{*}{$\begin{array}{l}\text { Prevalence of non-urgent } \\
\text { visits (\%) (SD)) }\end{array}$} & \multicolumn{2}{|l|}{$\begin{array}{l}\text { Paris } \\
34.6 \text { (3.6) }\end{array}$} & \multicolumn{2}{|l|}{$\begin{array}{l}\text { Besançon } \\
28.8 \text { (3.7) }\end{array}$} \\
\hline & Sensitivity * & Specificity + & Sensitivity * & Specificity $f$ \\
\hline \multicolumn{5}{|l|}{ Observers (\% (SD)) } \\
\hline Expert 1 & $34.8(3.6)$ & $90.4(1.6)$ & 27.0 & $95.8(1.0)$ \\
\hline Expert 2 & $59.7(3.7)$ & $81.9(1.9)$ & $55.6(4.1)$ & $82.2(2.0)$ \\
\hline Doctor & $99.4(0.6)$ & $88.2(2.1)$ & $82.0(4.2)$ & $95.4(1.5)$ \\
\hline \multirow[t]{2}{*}{ Nurse } & $95.2(2.9)$ & $100 \quad(0.0)$ & $88.6(4.3)$ & $98.0(1.4)$ \\
\hline & $\begin{array}{l}\text { Non-urgent } \\
\text { visits \% }\end{array}$ & & $\begin{array}{l}\text { Non-urgent } \\
\text { visits \% }\end{array}$ & \\
\hline \multicolumn{5}{|l|}{ Observers } \\
\hline $\mathrm{ABCD}$ & 34.6 & & 28.8 & \\
\hline $\mathrm{ABD}$ & 34.7 & & 24.5 & \\
\hline BCD & 35.7 & & 30.5 & \\
\hline ACD & 33.0 & & 28.0 & \\
\hline $\mathrm{ABC}$ & 33.9 & & 27.6 & \\
\hline
\end{tabular}

^ Probability of detecting non -urgent cases among true non-urgent cases.

† Probability of detecting urgent cases among true urgent cases. referred by their GP in Besancon, compared with Paris, where most patients were self referred or transported by the police or a fire service or Red Cross ambulance (table 1). Subsequent hospital admission occurred in $34.5 \%$ of the Paris and $71.5 \%$ of the Besançon visits to the emergency department $(p<0.001)$. Among those who were not admitted, a higher percentage of Besançon patients than Paris patients had further investigations: $64.1 \%$ and $38.0 \%$ repectively had biological tests $(p<0.001), 44.8 \%$ and $33.2 \%$ respectively had an electrocardiogram $(p=0.02)$, and $49.0 \%$ and $34.3 \%$ respectively had radiograms $(p=0.003)$.

PREVALENCE OF NON-URGENT CARE IN THE TWO HOSPITALS

According to the judgement of the four observers, non-urgent care occurred on a mean(SD) of 34.6 (3.6)\% of the visits in Paris and 28.8 (3.7)\% in Besançon (table 2). These estimates were found to be stable when all the combinations of using three observers out of four were used (table 2). According to the doctor on duty, who was estimated to have the best sensitivity and specificity among the observers, these percentages were $32.7 \%$ in Paris and $26.9 \%$ in Besançon. This proportion was slightly different according to the month of study $(p=0.02)$. However, no seasonal effect was observed.

POPULATION VISITING FOR NON-URGENT CARE

The population of subjects defined as nonurgent was younger than the whole population. Their housing conditions were more precarious, and the group comprised a high proportion of homeless people. Subjects born outside of France (foreigners and immigrants), single persons living alone, and unemployed people were more frequent in the non-urgent group. More in this group had no health insurance coverage (table 3 ).

Fewer of the non-urgent cases were referred by a physician. A higher percentage was self referred. In Paris only, a higher number was transported by the police or by primary emergency care transportation (table 3 ).

In Paris, the reason for the visit to the emergency department according to the non-urgent patients compared with the other patients was less often non-specific symptoms (19.2 versus $27.3 \%$ ) or psychiatric problems (9.0 versus $18.9 \%$ ). In contrast, osteoarticular diseases were more frequent in Paris (22.0 versus $11.7 \%$, respectively; global comparison: $\mathrm{p}<0.001)$. The medical diagnosis confirmed the lower frequency of non-specific symptoms (6.4 versus $16.2 \%$ respectively) and also of circulatory diseases ( 1.2 versus $11.9 \%$ respectively), and the higher frequency of osteoarticular diagnosis $(17.9$ versus $5.1 \%)$ and social problems $(11.0$ versus $0.8 \%)(p<0.001)$ in Paris compared with Besançon. In Besançon the categories of reasons stated by the patient for the visit did not differ whether or not the visit was urgent. In contrast the medical diagnosis showed a lower proportion of diagnosis related to the circulatory (4.2 versus 
Table 3 Urgent and non-urgent visits to the emergency departments (ED) of two university hospitals in Paris and Besançon

\begin{tabular}{|c|c|c|c|c|c|c|}
\hline \multirow[b]{2}{*}{ Variables } & \multicolumn{3}{|c|}{ Visits to Paris ED } & \multicolumn{3}{|c|}{ Visits to Besançon ED } \\
\hline & $\begin{array}{l}\text { Urgent } \\
(n=400) \\
\%\end{array}$ & $\begin{array}{l}\text { Non-urgent } \\
(n=194) \\
\%\end{array}$ & $p$ & $\begin{array}{l}\text { Urgent } \\
(n=449) \\
\%\end{array}$ & $\begin{array}{l}\text { Non-urgent } \\
(n=165) \\
\%\end{array}$ & $p$ \\
\hline \multicolumn{7}{|l|}{ Age(y): } \\
\hline$<30$ & 23.8 & 29.7 & & 19.8 & 32.7 & \\
\hline $30-64$ & 55.1 & 57.7 & & 42.8 & 42.4 & \\
\hline$>=65$ & 21.1 & 12.6 & 0.04 & 37.4 & 24.8 & 0.0001 \\
\hline \multicolumn{7}{|l|}{ Birthplace: } \\
\hline France & 77.6 & 67.0 & 0.01 & 87.1 & 81.8 & 0.11 \\
\hline \multicolumn{7}{|l|}{ Housing conditions: } \\
\hline Stable & 82.7 & 71.7 & & 76.4 & 64.9 & \\
\hline Homeless & 4.7 & 14.4 & & 1.0 & 4.0 & \\
\hline Precarious housing & 8.4 & 11.0 & & 17.9 & 23.2 & \\
\hline Institutions for elderly & 4.2 & 2.9 & 0.001 & 5.5 & 7.9 & 0.02 \\
\hline \multicolumn{7}{|l|}{ Referral: } \\
\hline Self referral & 27.7 & 60.1 & & 7.0 & 27.5 & \\
\hline General practitioner & 5.0 & 2.8 & & 53.7 & 36.3 & \\
\hline Ambulatory emergency care & 12.4 & 6.2 & & 6.3 & 6.9 & \\
\hline \multicolumn{7}{|l|}{ Police, fire service } \\
\hline Red Cross, ambulance & 37.3 & 20.2 & & 16.7 & 13.1 & \\
\hline Family, relatives & 14.6 & 9.0 & & 7.5 & 11.3 & \\
\hline Others (referrals from hospitals, clinics..) & 3.0 & 1.7 & 0.0001 & 8.8 & 5.0 & 0.0001 \\
\hline \multicolumn{7}{|l|}{ Health insurance: } \\
\hline "Sécurité sociale" & 91.0 & 79.9 & 0.002 & 99.4 & 97.8 & 0.001 \\
\hline \multicolumn{7}{|l|}{ Usual source of care: } \\
\hline General practitioner & 82.8 & 52.9 & & 94.6 & 88.6 & \\
\hline Hospital emergency department & 7.5 & 24.7 & & 2.1 & 7.9 & \\
\hline Other ambulatory care & 9.8 & 22.4 & 0.0001 & 3.2 & 3.6 & 0.009 \\
\hline Hospital admission & 56.1 & 8.8 & 0.0001 & 87.7 & 42.1 & 0.001 \\
\hline Tetanus immunisation & 70.2 & 58.8 & 0.01 & 63.6 & 61.5 & NS \\
\hline \multicolumn{7}{|l|}{ Alcohol consumption } \\
\hline $\begin{array}{l}(\text { glasses/d)(mean(SD)) } \\
\text { Tobacco consumption }\end{array}$ & $1.9(3.4)$ & $3.3(8.0)$ & 0.003 & $2.1(5.3)$ & $2.5(7.2)$ & 0.50 \\
\hline (cigarettes/d)(mean $(\mathrm{SD}))$ & $5.7(8.4)$ & $6.8(8.3)$ & 0.17 & $6.6(12.3)$ & $7.0(11.0)$ & 0.74 \\
\hline
\end{tabular}

Table 4 Demographic, social factors and health care utilisation associated with a non-urgent visit to two emergency departments in Paris and Besançon: logistic regression

\begin{tabular}{|c|c|c|c|c|c|}
\hline Variables & $\beta$ & $S D$ & $p$ & Odds ratio & $(95 \% C I)$ \\
\hline Age $(y)$ & -0.011 & -0.004 & 0.001 & 0.001 & - \\
\hline \multicolumn{6}{|l|}{ Housing conditions: } \\
\hline Precarious housing & 0.317 & 0.234 & 0.17 & 1.37 & $(0.87,2.17)$ \\
\hline Homeless & 0.699 & 0.425 & 0.10 & 2.01 & $(0.87,4.63)$ \\
\hline Housing for elderly & 1.183 & 0.423 & 0.005 & 3.26 & $(1.42,7.48)$ \\
\hline \multicolumn{6}{|l|}{ Referral: } \\
\hline General practitioner & - & - & - & 1 & \\
\hline Ambulatory emergency care & -0.681 & 0.392 & 0.08 & 0.51 & $(0.23,1.09)$ \\
\hline \multicolumn{6}{|l|}{ Police, fire service, } \\
\hline Red Cross, ambulance & -0.818 & 0.258 & 0.001 & 0.44 & $(0.27,0.73)$ \\
\hline Family, relatives & -0.466 & 0.327 & 0.15 & 0.63 & $(0.33,1.19)$ \\
\hline Self referral & 0.472 & 0.206 & 0.02 & 1.60 & $(1.07,2.40)$ \\
\hline \multicolumn{6}{|l|}{ Usual source of care: } \\
\hline General practitioner & - & - & - & 1 & \\
\hline Emergency department & 0.981 & 0.305 & 0.001 & 2.67 & $(1.47,4.85)$ \\
\hline Other ambulatory structures & 0.936 & 0.293 & 0.001 & 2.55 & $(1.44,4.53)$ \\
\hline Stated chronic disease & -0.478 & 0.181 & 0.01 & 0.62 & $(0.43,0.88)$ \\
\hline \multicolumn{6}{|l|}{ Birthplace: } \\
\hline France & & & & 1 & \\
\hline Outside of France & 0.477 & 0.189 & 0.01 & 1.61 & $(1.11,2.33)$ \\
\hline
\end{tabular}

$9.8 \%)$ or neurological system (4.2 versus $8.2 \%)(\mathrm{p}<0.001)$ for non-urgent patients.

Fewer non-urgent patients stated that they had a general practitioner. Conversely, a high percentage reported that they used the emergency department as a source of primary care (table 3). In Paris, subjects who came for nonurgent care had a higher alcohol consumption than others. Their prevention status was lower as far as tetanus immunisation was concerned (table 3). Their awareness of their total cholesterol levels was lower. Among nonurgent patients, $37.7 \%$ had had their total cholesterol concentration measured compared with $55.8 \%$ of urgent patients $(p<0.001)$. Similarly, they were less concerned by health coverage in the media; $45.3 \%$ of the non- urgent patients compared with $29.3 \%$ of other patients stated that they never watched TV programmes on health $(\mathrm{p}<0.001)$.

When the analysis was performed after exclusion of the homeless people, the results were basically unchanged. Among 1048 persons, $28.3 \%$ of the visits were non-urgent. When the visit was non urgent, the patients were younger $(17.8 \%$ are 65 years and more compared with $29.6 \%$ among other subjects; $\mathrm{p}<0.001)$, more often single $(30.6 \%$ versus $22.3 \%$; $\mathrm{p}<0.01$ ), born outside of France $(27.6 \%$ versus $18.0 \%$; $p<0.001)$; a higher proportion was unemployed (10.2 versus $7.6 \%$ ), and a lower percentage was retired $(16.8 \%$ versus $29.5 \%)(p=0.002)$. Similarly, a lack of any regular source of health care 
(10.6\% versus $5.8 \% ; \mathrm{p}<0.001)$, of a GP (73.9\% versus $90.7 \% ; p<0.001)$ was observed. Social category and educational level were not significantly different. Less interest in watching television programmes concerning health $(37.0 \%$ versus $26.4 \%$ answered that they never used to look at such a programme; $\mathrm{p}<0.05$ ) and a lower immunisation status $(61.9 \%$ versus $68.0 \% ; p=0.07)$ are similar to the whole population of patients.

Since the tendencies were concordant in the two cities and no interaction was observed between any variable and the hospital, the results of the two cities were pooled for the multivariate analysis. Two successive analyses were performed. In the first model, the only variables included were demographic and social (age, sex, birthplace, housing conditions, occupational activity, educational level, matrimonial status, social support, and study period), in order to describe which of these characteristics were predictive of non-urgent care. Young age, homelessness (OR: 3.41; 95\% CI 1.92, 6.05), precarious housing (OR: 1.49; $95 \%$ CI $1.000,2.22)$, or birthplace outside France (OR: 1.77 ; 95\% CI 1.27, 2.47) were associated with non-urgent care.

In the second model, variables describing the usual health care utilisation (health insurance, usual source of health care, reference to the emergency department, number of previous visits at the emergency department, a stated chronic disease, the prevention tracers (tetanus immunisation), alcohol, and tobacco consumption) were added in order to assess which aspects of them were related to the utilisation of the emergency department as a source of non-urgent care. The lack of a GP , birthplace outside of France, and being self referred at the emergency department, were positively associated with non-urgent care, whereas a chronic disease was negatively associated (table 4 ).

\section{Discussion}

Despite major differences between the two hospitals and their patients, about one third of the visits at these two emergency departments were found to be non-urgent. The population of patients for whom the visit was classified as non-urgent was socially deprived, these people had no usual source of care, and their level of risk factors was high.

This result was observed despite major differences between the two emergency department settings. These differences concerned the following: (1) the population attending the emergency department - in Paris, the patients were younger and more of them were homeless and born outside of France; (2) the primary health care system surrounding the hospital in Besançon, the GP was often the person who referred the patient and many more people stated they had a GP; and (3) the hosptial admission rate - the admission rate was twice as high in Besançon as in Paris. Despite these differences, the proportion of non-urgent visits was only slightly lower in Besançon. A surprisingly high proportion of non-urgent visits was followed by hospital admission in Besançon.
These results suggest the need to assess the appropriateness of hospital admissions from the emergency department. ${ }^{16}$

The percentage of non-urgent visits should be interpreted with caution. In fact, to define a visit as urgent or non-urgent is extremely difficult. Several approaches have been proposed in the literature. Some studies have restricted the definition of 'emergency' to a medical one, assessing the emergency in relation to the period of time within which care should be given. ${ }^{6}{ }^{17}$ The result of this approach is to neglect subjective emergencies. Similarly, a list of symptoms ${ }^{18}$ would be far too long if it were to include subjective emergencies. None of these methods was considered appropriate to our goal. Some criteria were thus drawn up before beginning the study to define nonurgent visits. The true value of the prevalence was then estimated according to the opinion of four experts, using the same set of criteria. The estimate was found to be fairly stable when one expert after another was removed from the panel.

Estimates of the prevalence of non-urgent visits agree with observations from other European hospitals. In France, similar results (28\%) have been published for a paediatric emergency department. ${ }^{3}$ In Sweden, 39\% of the visits were found to be non-urgent. ${ }^{6}$ In London, according to an assessment performed by a nurse, $41 \%$ of the visits were related to primary health care. ${ }^{5}$ In the USA, the percentages were usually higher, from $68 \%$ in a poor neighborhood in Los Angeles ${ }^{19}$ to $87 \%$ in a study from San Francisco. ${ }^{17}$ A study from the American Hospital Association in four US cities reported percentages ranging from 35 to $51 \%$. $^{20}$

These visits have been described as inappropriate $^{17}$ and the patients as abusers in some studies $^{1218}$ Although similar in its methodology, our approach was conceptually different. The same phenomenon, non-urgent care at the emergency department, can be seen from a public health point of view as a way of assessing patients' health care needs. Despite a generalised health insurance system in France, the population which used the emergency department for primary health care was very similar to that reported in previous European and US studies. ${ }^{182122}$ The unemployed, young persons, the homeless and those with precarious housing, patients with no health insurance, and those born outside of France were over-represented. This picture resembles strongly that in the US reports, where the emergency department tends to provide primary health care to poor, deprived, inner city, mostly black communities. ${ }^{18-2122}$

Our results emphasise the problems confronting the health care system in France. Due to administrative barriers, a large number of people do not benefit from the national health insurance system. Even among those covered by the national system, one person out of five, mainly among lower social categories, does not benefit from a complementary private or mutual health insurance. ${ }^{23}$ Independently of these financial factors, sociocultural factors have been shown to influence health care utili- 
sation and, particularly, a high hospital utilisation among lower social categories. ${ }^{24}$ All these factors contribute independently to increase the use of the emergency department as a primary health care facility and should stimulate research on the efficacy of primary health care in France as far as underprivileged populations are concerned.

The lack of a general practitioner, who is supposed to provide primary care in France, was found to be a major risk factor for non-urgent visits. Similarly, being self referred to the emergency department was a risk factor for non-urgent visits. These observations emphasise the position of the emergency department as a primary care structure when other ambulatory structures are not available or not used. The pathways to the hospital, in the case of medical emergency, have been developed in France through a network of mobile intensive care units. The same evaluation and efforts could now be devoted to the relationship between the ambulatory primary health care and the emergency department.

The assessment of health status in our study is insufficient to describe precisely the health of the patients. Given the difficulties of interviewing people in the waiting room of an emergency department and of interpreting a quality of life instrument at a moment when people are waiting for care, the only direct information recorded was the reason for attending and the diagnosis of the doctor on duty. The range of the problems involved was not very different from that found in a general population. ${ }^{25}$ There is, however, indirect evidence suggesting that the health of those who use the emergency department for non-urgent visits is poor. In a longitudinal study in Sweden, the health status of these heavy users of care was shown to be low, as witnessed by a high mortality rate. ${ }^{26}$ Further evidence can be gained from the hypertension awareness in our study. Despite a similar mean blood pressure level in both groups, none of those using the emergency department for primary health care purposes as opposed to $16 \%$ of the other patients was aware of having hypertension, suggesting that some hypertension was undetected in the former. It has been shown that these patients, who were characterised in our study by a lack of general practitioner, are at high risk for severe uncontrolled hypertension. ${ }^{27}$. In addition, as in our study, high alcohol and cigarette consumption were additional risk factors for severe uncontrolled hypertension as well as for cardiovascular diseases.

The status with regard to prevention was low among regular users of the emergency department and among patients visiting for nonurgent care. This was assessed by the low percentages of tetanus immunisation and of patients who stated that they never looked at any health programmes on television or were unaware of their cholesterol levels.

Taken together, the lack of usual sources of care and the need for prevention among these patients describe a situation in which patients need some continuity of care. They use a health structure that is, by definition, organised to provide acute care on a short term basis. For them, the visit to the emergency department has been called a missed opportunity, since the contact is usually limited to the acute symptoms or health problems. ${ }^{28}$ However, this visit might indeed be used for improving prevention and trying to organise continuity of care for these people. ${ }^{29} 30$ Some authors, however, have emphasised the difficulty in taking advantage of this opportunity, since regular users of the emergency department have characteristics which predict a low compliance with health programmes. ${ }^{30}$. The results of such an approach for an underserved population ${ }^{29}$ have thus to be assessed. ${ }^{28}$

\section{CONCLUSION}

Around one third of the visits to two emergency department were found to be nonurgent. This phenomenon has been observed in several countries, despite different health care systems. From a public health point of view, these patients should not be considered as 'inappropriate' or 'abusers'of the acute care system. Their health needs have been shown to be serious and they need continuity of care, a task for which the emergency department is not organised nowadays. The lack of primary health care utilisation before or instead of the emergency department has been repeatedly observed. These results suggest that we should evaluate precisely how the primary health care system might be used more by the groups described as non-urgent at the emergency department. The results of increased accessibility of primary health care, particularly in terms of opening hours as well as financially, should be assessed. Alternatively, the availability of primary health care at the emergency department, providing continuity of care outside of working hours, might be evaluated.

We acknowledge the help of the personnel, the nurses, and the managerial staff of the two emergency departments of the PitiéSalpetrièreHospital in Paris and the Jean Minjoz Hospital in Besançon. Thanks to Pierre Lombrail for fruitful discussions on
this topic. This work was supported by a grant CNAMTSthis topic. This work was supported by a grant CNAMTS-
INSERM No 3AM049 and from the Déleggation à la Recherche INSERM No 3AM049 and from the Délégation à la Recherche
Clinique de l'Assistance-Publique Hopitaux de Paris No 922205.

1 Gaussens E. Les urgences à Paris: bilan du plan urgence de l'Assistance Publique-Hôpitaux de Paris. Techniques Hospitalières. 1993;578:21-35

2 Steg A. L'urgence à l'hôpital. Rapport présenté au Conseil économique et social. Séances des 11 et 12 Avril 1989. fournal Officiel de la République française no 4123.

3 Lombrail P, Alfaro C, Vitoux-Brot C, Brodin M, Bourrillon A, Beaufils $F$. Analyse du recrutement en urgence d un hopital pédiatrique, conséquences sur l organ
offre de soins. Arch Fr Pediatr 1993;50:313-7.

4 Beaufils F, Brunschwig O, Nardou M. Quels sont les enfants amenés aux urgences médicales pédiatriques? Fournées parisiennes de pédiatrie. Paris: Flammarion Médecine Sciences, 1982:345-53.

5 Dale J, Green J, Reid F, Glucksman E. Primary care in the accident and emergency department: I Prospective identification of patients. BMF 1995;311:423-6.

6 Magnusson G. Utilization of a hospital emergency department in Stockholm: the effect of age, sex, and marital status. Scand $\mathcal{F}$ Soc Med 1980;81:141-8.

7 Gill JM: Nonurgent use of the emergency department: appropriate or not? Ann Emerg Med. 1994;24:953-7

8 Lang T, Ducimetière P. Premature cardiovascular mortality in France: divergent evolution between social categories from 1970 to 1990. Int F Epidemiol 1995;24:331-9.

9 Shortell SM. Continuity of medical care. Conceptualization and measurement. Med Care 1976;XIV:377-91.

10 INSEE. Nomenclature des professions et catégories socioprofessionnelles. Paris: INSEE, 1993. 
11 Jamoule $\mathrm{M}$, Roland $\mathrm{M}$. Classification internationale des soins primaires. Lyon: Lacassagne Ed, 1992;293.

12 Malone RE. Heavy users of emergency services: social construction of a policy problem. Soc Sci Med, 1995; 40:469-77

13 SAS. SAS user's guide: statistics. Version 6, 4th edition. Cary NC: SAS, 1990

14 Bertrand P., Benichou J., Chastang C. Estimation par la méthode de Hui et Walter de la sensibilité et de la spécificité d'un test diagnostique en l'absence d'un test de référence: résultats d'une étude de simulation. Rev Epidém référence: résultats d'une étude

15 Bertrand P. Paris:University Paris VII. PhD Dissertation. 1996 In press. -

16 Lang T, Davido A, Logerot H, Meyer L. Appropriateness of admissions: the French experience. International fournal of Quality in Health Care 1995;7:233-38.

17 Grumbach K, Keane D, Bindman A. Primary care and public emergency department overcrowding Am $\mathcal{F}$ Publ Health, 1993;83:372-8.

18 Derlet R. W., Nishio D.A. Refusing care to patients who present to an emergency department Ann Emerg Med, 1993, 19:262-7.

19 Baker DW, Stevens CD, Brook RH. Regular source of ambulatory care and medical care utilization by patients presenting to a public hospital emergency department. presenting to a public hosp

20 Mauskopf J, Turner BJ, Markson LE, Houchens RL, Fannng TR, McKee L. Patterns of ambulatory care for Fannng TR, McKee L. Patterns of ambulatory care for
AIDS patients, and association with emergency room use. Health Services Res 1994;29:489-510.
21 Hayward R, Bernard A, Freeman H, Corey C. Regular source of ambulatory care and access to health services. Am f Public Health 1991;81:434-5.

22 Shesser R., Kirsch T., Smith J., Hirsch R. An analysis of use by patient with minor ilness. Ann Emerg Med 1991;20:743-8.

23 Bocognano A, Grandfils N, Lecomte T, Mizrahi A, Mizrah A. Enquête sur la santé et la protection sociale en 1991. A. Enquête sur résultats. Paris, CREDES, No 934, 1992.

24 Mormiche P. L'accès aux soins : évolution des inégalités entre 1980 et 1991 . Economie et Statistiques 1995;282:3-19. 25 Sermet C. De quoi souffre-t-on ? Description et évolution de la morbidité déclarée 1980-1991. Solidarité Santé 1994 1:37-56.

26 Hansagi H, Edhag O, Allebeck P. High consumers of health care in an emergency unit: how to improve their quality of care. Quality Assurance in Health Care 1991;3:51-62.

27 Shea S, Misra D, Ehrlich MH, Field L, Francis CK. Predisposing factors for severe, uncontrolled hypertension in an inner-city minority population. $N$ Engl f Med 1992; 327:776-81.

28 Lang T, Lombrail P, Fouriaud C, Jacquinet-Salord MC Mahé I. Hôpital, médecine du travail et correction des inéalités dans le domaine de la prévention. Rev Epidém et Santé Publ 1990;38:281-6

29 Levine DM, Becker DM, Bone LR, Hill MN, Tuggle MB Zeger SL. Community-academic health center partnerships for underserved minority populations. $¥ A M A 1994$ ships for under

30 Purdie F, Honigman B, Rosen P. The chronic emergency department patient. Ann Emerg Med 1981;10:298-301. 